\title{
Corrigendum: Matrix Metalloproteinases and Blood-Brain Barrier Disruption in Acute Ischemic Stroke
}

\author{
Shaheen E. Lakhan ${ }^{1,2 *}$, Annette Kirchgessner ${ }^{1,3}$, Deborah Tepper $^{2}$ and Aidan Leonard ${ }^{1}$ \\ 'Biosciences Department, Global Neuroscience Initiative Foundation, Beverly Hills, CA, United States, ${ }^{2}$ Neurological \\ Institute, Cleveland Clinic, Cleveland, OH, United States, ${ }^{3}$ School of Health and Medical Sciences, Seton Hall University, \\ South Orange, NJ, United States
}

Keywords: matrix metalloproteinases, blood-brain barrier, stroke, caveolin-1, reactive oxygen species

\section{A corrigendum on}

Matrix Metalloproteinases and Blood-Brain Barrier Disruption in Acute Ischemic Stroke by Lakhan SE, Kirchgessner A, Tepper D, Leonard A. Front Neurol (2013) 4:32. doi: 10.3389/ fneur.2013.00032

\section{Missing Citation 1}

In the original article, Cucullo et al. (2011) was not cited in the article. The citation has now been inserted in "Structural Components of the BBB/Neurovascular Unit," Paragraph 1 and should read:

The $\mathrm{BBB}$ is a dynamic interface between the peripheral circulation and the CNS. It controls the influx and efflux of biological substances needed for the brain metabolic processes, as well as for neuronal function. Thus, the functional and structural integrity of the BBB is vital in maintaining

OPEN ACCESS

Edited by: Ashfaq Shuaib,

University of Alberta, Canada

Reviewed by:

Carine Ali,

University of Caen Normandy,

France

*Correspondence: Shaheen E. Lakhan slakhan@gnif.org

Specialty section: This article was submitted to Stroke, a section of the journal

Frontiers in Neurology

Received: 08 January 2018 Accepted: 14 March 2018 Published: 04 April 2018

Citation: Lakhan SE, Kirchgessner A, Tepper D and Leonard A (2018) Corrigendum:

Matrix Metalloproteinases and Blood-Brain Barrier Disruption in

Acute Ischemic Stroke.

Front. Neurol. 9:202. doi: 10.3389/fneur.2018.00202 brain homeostasis (Cucullo et al., 2011).

\section{Missing Citation 2}

In the original article, Klein and Bischoff (2011) was cited in the article except for a single instance. The citation has now been inserted in "MMP-9 (Gelatinase B)," Paragraph 1 and should read:

Matrix metalloproteinase-9 (gelatinase B), first described in neutrophils in 1974 (Sopata and Dancewicz, 1974), is expressed as a $92-\mathrm{kDa}$ proenzyme, which can be activated to the $83-\mathrm{kDa}$ mature enzyme (Klein and Bischoff, 2011).

\section{Missing Citation 3}

In the original article, Malemud (2006) was cited in the article except for a single instance. The citation has now been inserted in "Matrix Metalloproteinases," Paragraph 1 and should read:

Most of the MMPs are synthesized as inactive latent enzymes. Conversion to the active enzyme is generally mediated by activator systems that include plasminogen activator or the pro-hormone convertase, furin (Malemud, 2006).

\section{Text Correction}

In the original article, there was an error. An incorrect citation was made to del Zoppo (2009) instead of Hawkins and Davis (2005).

A correction has been made to "Structural Components of the BBB/Neurovascular Unit," Paragraph 2:

Briefly, the anatomical substrate of the BBB is the cerebral microvascular endothelium, which together with the closely associated astrocytes, pericytes, neurons, and the ECM, constitute a "neurovascular unit" that is essential for the health and function of the CNS (Hawkins and Davis, 2005).

The authors apologize for these errors and state that these do no change the scientific conclusions of the article in any way.

The original article has been updated. 


\section{REFERENCES}

Cucullo, L., Hossain, M., Puvenna, V., Marchi, N., and Janigro, D. (2011). The role of shear stress in Blood-Brain Barrier endothelial physiology. BMC Neurosci. 12:40. doi:10.1186/1471-2202-12-40

del Zoppo, G. J. (2009). Inflammation and the neurovascular unit in the setting of focal ischemia. Neuroscience 158, 972-982. doi:10.1016/j.neuroscience.2008. 08.028

Hawkins, B. T., and Davis, T. P. (2005). The blood-brain barrier/neurovascular unit in health and disease. Pharmacol. Rev. 57, 173-185. doi:10.1124/pr.57.2.4

Klein, T., and Bischoff, R. (2011). Physiology and pathophysiology of matrix metalloproteinases. Amino Acids 41, 271-290. doi:10.1007/s00726-010-0689-x
Malemud, C. (2006). Matrix metalloproteinases (MMPs) in health and disease: an overview. Front. Biosci. 11, 1696-1701. doi:10.2741/1915

Conflict of Interest Statement: The authors declare that the research was conducted in the absence of any commercial or financial relationships that could be construed as a potential conflict of interest.

Copyright (c) 2018 Lakhan, Kirchgessner, Tepper and Leonard. This is an open-access article distributed under the terms of the Creative Commons Attribution License (CC BY). The use, distribution or reproduction in other forums is permitted, provided the original author(s) and the copyright owner are credited and that the original publication in this journal is cited, in accordance with accepted academic practice. No use, distribution or reproduction is permitted which does not comply with these terms. 